\title{
Estudos de Gênero na Psicologia (1980-2016): Aproximações e Distanciamentos
}

\author{
Jacy Correa Curado ${ }^{1}$ \\ Ana María Jacó-Vilela ${ }^{2}$ \\ ${ }^{1}$ Universidade Federal de Mato Grosso do Sul, MS, Brasil. \\ ${ }^{2}$ Universidade do Estado do Rio de Janeiro, RJ, Brasil.
}

Resumo: Este artigo apresenta a emergência e a história dos estudos de gênero na psicologia a partir da consideração sobre a relevância de usar a noção de" gênero" como categoria de análise histórica para pensar o campo disciplinar da psicologia. Isto nos possibilita compreender os efeitos teóricos, metodológicos e epistemológicos na produção de conhecimento. A partir de uma pesquisa bibliográfica realizada na base de dados SciELO, foram analisados 153 artigos de três periódicos da psicologia. Estes, com seus 402 autores(as) e 191 instituições, foram agrupados em 15 categorias temáticas. Uma análise quali-quantitaviva encontrou resultados que apontam para desigualdades de gênero na autoria dos artigos e uma presença marcante das universidades públicas entre as instituições que mais publicam na área. A psicologia, quando debate gênero, o faz por meio de discussões temáticas de campos de conhecimento tradicionais - como saúde, educação e trabalho, típicos da segunda onda do feminismo. As questões identitárias e sobre sexualidades se destacam em produções mais recentes. Da articulação entre gênero e psicologia com foco nas discussões teórico-epistemológicas, constatamos que, embora haja publicações que apontem críticas à psicologia questionando o uso descritivo de gênero, bem como à objetividade do conhecimento e à universalidade do sujeito, ainda se verificam dificuldades em sair do lugar androcêntrico, etnocêntrico e cisheteronormativo que caracteriza a produção psicológica. O estudo aponta a necessidade de maior sensibilização e ampliação de espaços de discussão entre gênero e psicologia para que se possa resistir às invisibilidades ainda tão persistentes nesse campo disciplinar de conhecimento.

Palavras-chave: Psicologia, Gênero, Pesquisa em Base de Dados, Epistemologia.

\section{Gender Studies in Psychology (1980-2016): Approximations and Distancing}

\begin{abstract}
This article addresses the emergence of gender studies in psychology and how the adoption of gender as a category of historical analysis to interpret the disciplinary field of psychology had theoretical, methodological, and epistemological effects on knowledge production. A bibliographic search on the SciELO database was performed and 153 articles analyzed. The studies retrieved, grouped into 15 thematic categories, were from three psychology journals and authored by 402 investigators from 191 institutions. Qualitative-quantitative analysis showed gender inequalities in authorship and a marked presence of public universities among the institutions that most publish in this area. Psychology was found to debate gender in the form of thematic discussions in traditional fields of knowledge - such as health, education, and work typifying the second wave of feminism. Identity and sexuality issues predominated in more recent productions. The articulation between gender and psychology, with a focus on theoreticalepistemological discussions, showed that, despite the presence of studies voicing criticism of psychology, questioning a descriptive use of gender, as well as against objective knowledge and the universality of the subject, difficulties remain in breaking with the androcentric, ethnocentric, classist, cisheteronormative locus that characterizes psychological production. The study emphasizes the need for increased awareness and forums for discussions involving gender and psychology, enabling us to resist to invisibilities that persist in this disciplinary field of knowledge.
\end{abstract}

Keywords: Psychology, Gender Studies, Database Research, Knowledge. 


\title{
Estudios de Género en la Psicología (1980-2016): Aproximaciones y Distanciamientos
}

\begin{abstract}
Resumen: El artículo presenta la emergencia de los estudios de género en la psicología. El uso de género como una categoría de análisis histórico para pensar el campo disciplinar de la psicología ha posibilitado comprender los efectos teóricos, metodológicos y epistemológicos en la producción de conocimiento. A partir de la investigación bibliográfica realizada en la base de datos SciELO, se analizaron 153 artículos de 3 revistas de psicología, 402 autores y 191 instituciones agrupadas en 15 categorías temáticas. El análisis cuali-cuantitativo ha revelado resultados que indican desigualdades de género en la autoría de los artículos y una presencia destacada de las universidades públicas, entre las que más publican en el área. La psicología cuando debate género lo hace mediante discusiones temáticas en campos de conocimiento tradicionales, como salud, educación y trabajo, típicos de la segunda onda del feminismo. Las cuestiones de identidad y de sexualidad se destacan en publicaciones más recientes. De la articulación entre género y psicología con enfoque en discusiones teóricas y epistemológicas, se ha constatado que aunque hay publicaciones que indican críticas a la psicología cuestionando el uso descriptivo de género, así como la objetividad del conocimiento y la universalidad del sujeto, todavía se verifican dificultades en salir del lugar androcéntrico, etnocéntrico, clasista y cisheteronormativo que caracteriza la producción psicológica. El estudio señala la necesidad de una mayor sensibilización y ampliación de espacios de discusión entre género y psicología para que se pueda resistir a las invisibilidades aún tan persistentes en este campo disciplinar de conocimiento.
\end{abstract}

Palabras clave: Psicología, Género, Investigación en Base de Datos, Epistemología.

Este artigo apresenta a emergência do conceito de gênero na psicologia, buscando traçar um pouco de seu percurso histórico. Entendemos que gênero é um conceito em disputa, marcado por heterogeneidades temática, teórica e metodológica. O nosso objetivo é apresentar os diferentes usos desse conceito e entender como "gênero" têm influenciado as teorizações e metodologias da psicologia em sua história recente. Reconhecemos que outros campos disciplinares passaram por importantes transformações teórico-metodológicas ao inserir essa perspectiva em seus estudos e pesquisas. Os questionamentos sobre o papel da mulher, as relações de gênero e a vida privada trouxeram contribuições para a historiografia social (Shoiet \& Pedro, 2007). A emergência dos estudos de gênero impactou também a produção de conhecimento nas áreas de sociologia, antropologia e filosofia no Brasil (Saffioti, 2015; Hirata, 2009; Heilborn, 2004). Reconceituações do trabalho produtivo e reprodutivo, do trabalho doméstico, oriundas das críticas que autoras (Kergoat, 2009; Federici, 2019; Hirata, 2009) denominam "Divisão Sexual do Trabalho", alteraram as formas das contabilidades e políticas econômicas dos organismos internacionais e nacionais.

Esses são alguns exemplos das contribuições e transformações ocorridas nesses campos disciplinares que nos levam a perguntar: E na psicologia? Qual é a importância dos estudos de gênero na psicologia? Quais temáticas e problemas de gênero são priorizados nesse debate? A inserção da perspectiva de gênero altera o modo de se fazer psicologia no Brasil, particularmente no campo da Psicologia Social?

Esses, entre outros questionamentos, inspiraram-nos a realizar esta pesquisa de estágio pós-doutoral no Laboratório Clio Psyché da Universidade do Estado do Rio de Janeiro (UERJ) intitulada "A história dos estudos de gênero na psicologia: aproximações e distanciamentos" (1980-2016), da qual apresentaremos os resultados parciais neste artigo.

\section{História de gênero ou história das mulheres? Que diferença faz?}

A multiplicidade semântica da palavra "gênero" ainda se encontra em construção, com alguns 
consensos e estabilidades, mas ainda passível de disputas - o que gera ampla discussão sobre os diferentes usos do termo.

A emergência do conceito de gênero ocorre posteriormente à constituição do campo de História das Mulheres, após as críticas ao racionalismo abstrato e ao universalismo presentes na noção de sujeito da História Clássica. Essas perspectivas se alinharam às mudanças trazidas pela Filosofia da Ciência, como as do "revisionismo neomarxista, Escola de Frankfurt, historistas, historiadores das mentalidades e do discurso, no sentido da desconstrução de Derrida ou na linha histórica de Foucault" (Dias, 1992, p. 43).

Ao diversificar os objetos de investigação histórica, as mulheres se tornam objeto e sujeito da história. Contudo, o uso de "mulheres" como categoria homogênea de análise histórica tornou-se um problema e a discussão de uma identidade múltipla que abarcasse as diferenças entre as mulheres foi sendo questionada. De uma pretensa identidade única entre as mulheres, há um apelo para a existência de múltiplas identidades, como discutem as historiadoras Soihet e Pedro:

Mulheres negras, índias, mestiças, pobres, trabalhadoras, muitas delasfeministas, reivindicaram uma 'diferença' - dentro da diferença. Ou seja, a categoria 'mulher', que constituía uma identidade diferenciada da de 'homem', não era suficiente para explicá-las (Soihet \& Pedro, 2007, p. 287).

Outra problemática apontada sobre a historiografia das mulheres trata dos limites do uso da abordagem descritiva, acusada de criar um apêndice, uma história isolada e exclusiva das mulheres, que não conseguia alterar a história mainstream, como aponta a historiadora Tilly:

Os melhores trabalhos sobre história das mulheres ... não estudam a vida das mulheres de uma maneira isolada: eles se esforçam por vincular estas vidas a outros temas históricos, como o poder das ideias ou as forças que governam as transformações estruturais (Tilly, 2007, p. 41).

Transformar a história das mulheres em fato histórico foi um desafio que também fez avançarem outros domínios da história. Nesse contexto de problematização emerge o conceito de gênero trazendo novas perspectivas para a historiografia. Não há um rompimento com a perspectiva já consolidada da História das Mulheres; pelo contrário, existe uma persistência de muitos dos pressupostos, preocupações e metodologias de pesquisa, que também reformularam ou contestaram várias outras formas de fazer história (Soihet \& Pedro, 2007). O problema parte do "como", em situações concretas e específicas, as diferenças de gênero são percebidas e organizam a construção das relações sociais. Gênero, assim, poderia ser analisado em todo e qualquer fenômeno e relação, não sendo exclusivo de nenhum domínio ou área específica.

Um dos textos importantes na constituição do campo de estudos da História de Gênero é da historiadora americana Joan Wallach Scott, que publicou, em 1986, na revista Historical American Review o artigo "Gender: A useful category of Historical Analysis", considerado um dos mais lidos e citados textos da história de gênero. No Brasil, seu artigo foi traduzido primeiramente por uma ONG feminista, Soscorpo, em 1992, e posteriormente publicado pela Revista Educação e Realidade em 1995 (Scott, 1995/2007). A noção de gênero expressa no artigo também foi traduzida para materiais educativos dos movimentos sociais e de mulheres e usada pelos documentos públicos de programas governamentais.

A autora diz, em uma entrevista concedida para importantes acadêmicas feministas brasileiras, que ignorava o sucesso do referido artigo no Brasil, "um país que confessa conhecer pouco, e se mostrou agradavelmente surpresa ao saber das inúmeras citações que ele tem merecido" (Grossi, Helborn, \& Rial, 1998, p. 115). Para as historiadoras Soihet \& Pedro (2007), esse tem sido, certamente, um dos mais citados nas discussões que pretendem abordar a categoria gênero nas análises da pesquisa histórica. Não há quem pesquise tal categoria analítica que não cite essa obra como precursora de estudos de gênero.

Para superar as críticas lançadas ao modo como foi estudada a "história das mulheres" (por volta da década de 1970) e mostrar por que tal abordagem teve tão pouco impacto, a autora sugere o uso do conceito de gênero como uma categoria útil de análise histórica para ampliar as discussões e analisar de modo mais rigoroso o processo de como ocorre e por que se reproduz a invisibilidade da mulher no processo de produção do conhecimento histórico. O importante seria não somente descrever a condição das mulheres na história, mas apontar as desigualdades de gênero e 
modificar as representações dos grupos deixados fora da história em razão da raça, etnicidade e classe, assim como pelo gênero (Scott, 1995/2007). Nessa abordagem de gênero, a história se configura não apenas como o registro das mudanças da organização social dos sexos, mas também, de maneira crucial, como participante da produção do saber sobre a diferença sexual. Ao ser questionada sobre qual seria, então, o papel do historiador ao estudar as relações de gênero, a autora sugere pensar como as hierarquias de gênero são construídas e legitimadas ao longo do tempo e nos mais diversos contextos. Mais especificamente, afirma que

Examinar gênero concretamente, contextualmente econsiderá-lo um fenômeno histórico, produzido, reproduzido e transformado em diferentes situações ao longo do tempo ... A história não é mais a respeito do que aconteceu a homens e mulheres e como eles reagiram a isso, mas sim a respeito de como os significados subjetivos e coletivos de homens e mulheres, como categorias de identidades foram construídos (Scott, 2007, p. 19).

Ao deslocar a questão de como fazer história de gênero para outro campo disciplinar, Scott (1995/2007) sugere que devemos tomar uma disciplina enquanto analista e produtora de saber cultural, dado que o que está em jogo é uma teoria epistemológica que oferece um método de análise dos processos pelos quais os significados são constituídos e pelos quais nós constituímos os significados. A importância de usar gênero como uma categoria de análise histórica para pensar a psicologia decorre da possibilidade de problematizar, de forma mais complexa e múltipla, as relações entre gêneros na contemporaneidade, inspirar desafios críticos ao nosso campo disciplinar e se tornar um modo de compreender criticamente como a psicologia opera enquanto lugar da produção do saber de gênero.

\section{A emergência dos estudos de gênero e as ondas do feminismo}

No Brasil, a emergência do conceito de gênero ocorre a partir de meados da década de 1980 - não somente na academia, mas, sobretudo, nos movimentos sociais de mulheres e feministas, no bojo da luta pelos direitos sociais e políticos por ocasião da elaboração da Constituição Federal de 1988. Na época, buscávamos igualdade de direitos no mundo do trabalho - diferenças salariais, dupla jornada, garantia de licença maternidade e visibilidade do trabalho doméstico. Outros campos de luta abordados foram o direito de acesso à saúde integral da mulher, o direito de decidir sobre o próprio corpo e o planejamento familiar, além daquilo que se tornou o principal problema social a ser enfrentado pelas mulheres: todas as formas de violência contra a mulher. Até a elaboração da Constituição Cidadã não se ouvia, lia ou discutia a respeito da perspectiva de gênero, e a questão era debatida sob a égide do conceito de subordinação das mulheres em uma sociedade capitalista patriarcal. Os diálogos teóricos ocorriam principalmente baseados na concepção de patriarcado, sua relação com a teoria marxista e a psicanálise.

Não há consenso sobre os primeiros usos do conceito de gênero; há os que atribuem como precursora a obra $O$ segundo sexo, de Simone de Beauvoir (1948/2019), e a frase "Ninguém nasce mulher, torna-se mulher" (Beauvoir, 2019, p. 11) como a manifestação primeira do conceito de gênero; "ou seja, é preciso aprender a ser mulher, uma vez que o feminino não é dado pela biologia, ou mais simplesmente pela anatomia, e sim construído pela sociedade" (Saffioti, 2015, p. 160).

Outros atribuem os primórdios da formulação do conceito ao psiquiatra americano Robert Stoller, na publicação do livro Sex and gender: the development of masculinity and femininity, de 1968, em que introduz a palavra "gênero" para diferenciar-se do termo "sexo", que estaria somente associado às condições biológicas. O livro Sex and gender tratava de intervenções cirúrgicas em pessoas intersexuais e transgênero para adaptar a anatomia genital ao gênero desejado. Para Stoller, o sentimento de ser mulher ou homem era mais importante do que as características anatômicas (Stoller, 1968).

Há ainda autores que apontam o uso do conceito de gênero no meio científico por John Money (1955), em meados do século XX, que já se diferenciava a ideia de gênero do conceito de sexo biológico, pois nem sempre "as expectativas sociais relacionadas às pessoas nascidas com determinadas configurações biológicas (femininas ou masculinas) redundará na identificação com certo gênero (homem ou mulher)" (Jesus \& Alves, 2012, p. 9).

Um dos textos importantes do uso do conceito de gênero é o “The traffic in women” (1975/1993), de Gayle 
Rubin, traduzido e publicado no Brasil em 1993. O texto tenta desenvolver uma teoria da opressão das mulheres valendo-se de conceitos da antropologia e da psicanálise e de um diálogo crítico com o pensamento marxista. Nas relações de parentesco, ele situa a mulher como uma mercadoria, o "meio" pelo qual a troca se realiza para estabelecer, ampliar e fortalecer relações sociais. E introduz, a partir dessa noção da "troca de mulheres", o conceito do "sistema sexo-gênero":

Uma série de arranjos pelos quais a matéria-prima do sexo humano e da procriação é moldada pela intervenção humana, social ... pelos quais uma sociedade transforma a sexualidade biológica em produtos da atividade humana, e nos quais essas necessidades sexuais transformadas são satisfeitas ... e deve ser reorganizado por meio da ação política (Rubin, 1975/1993, p. 3).

Para Rubin, gênero é concebido como uma divisão dos sexos imposta socialmente. É um produto das relações sociais de sexualidade. Gênero não é apenas uma identificação com um sexo; ele obriga também que o desejo sexual seja orientado para outro sexo. Aqui, alerta para a possibilidade de que a supressão do componente homossexual da sexualidade humana seja produto do mesmo sistema cujas regras e relações oprimem as mulheres. Sendo assim, seu texto pode ser considerado precursor da crítica de uma heteronormatividade compulsória nas teorias feministas, como fez mais tardiamente Butler (2003), motivo pelo qual sua obra tem sido retomada nos círculos acadêmicos atuais.

De Scott (1995/2007) é importante destacar que, para além da importância na historiografia, sua obra é também considerada um marco na teorização de gênero que tem sido usada para explicar as origens do patriarcado (ora alinhadas às críticas marxistas), ou se dividindo entre o pós-estruturalismo francês e as teorias anglo-americanas sobre as relações de objeto, inspirada em algumas escolas da psicanálise para discutir a produção e reprodução das identidades de gênero (Scott, 2007).

Para Scott, gênero "é um elemento constitutivo de relações sociais baseado nas diferenças percebidas entre os sexos, e o gênero é uma forma primeira de significar as relações de poder" (Scott, 1995, p. 86). Nesse enquadre referencial, um dos principais usos do termo gênero refere-se a uma construção social do feminino e do masculino. Isso implica a rejeição do biologicismo e essencialismo normalmente expressos como sexo ou diferença sexual. Rejeitar o determinismo biológico como análise das diferenças entre masculino e feminino implica questionar a hipótese de que existe um feminino universal, que naturalmente se identifica pelo fato de ser mulher, mãe e reprodutora. Em sua opção pós-estruturalista, a ênfase de Scott recai sobre o uso discursivo de gênero, pois é por meio da linguagem que é construída a identidade de gênero (Scott, 1995). Estas são concebidas não como uma questão de identidades individuais, unitárias e consistentes de homens e mulheres, mas se desenvolvem mediante peças de discursos organizadas em um sistema de significados que estão disponíveis aos indivíduos para darem sentido às suas posições, sendo historicamente reconhecidas como respostas femininas e masculinas. A diferença e diversidade intra e intergêneros - que se tornou uma grande questão epistemológica - expressa-se não só na produção de conhecimento, mas também em práticas e estratégias da ação política - ou seja, considerando as implicações dos eixos de classe social, raça, etnia e cultura que permeiam as relações de gênero. Dessa forma, vemos que a importância dessa abordagem reside na possibilidade de poder compreender a multiplicidade na constituição de gênero.

Em suas teorizações, Scott (2014) entende gênero como um conceito político em disputa, infinitamente em luta, um lugar perpétuo para a contestação política:

Gênero se torna um guia para a imaginação, regulação e transgressão nas sociedades e culturas que estudamos ... e longe de estar resolvido, como uma vez eu pensei que estava, gênero é uma questão permanente aberta: quando pensamos que foi resolvido, sabemos que estamos no caminho errado (Scott, 2014, p. 346).

Ampliando os limites discursivos desse conceito, Butler (2003) apresenta a noção de performatividade para problematizar as identidades de sexo/gênero, realizando uma potente crítica à exigência de se construir um sujeito do feminismo que exclua aqueles que não se conformam à ordem binária de uma heterossexualidade compulsória. Essa noção rompe com a clássica divisão entre sexo/ natureza por um lado e gênero/cultura por outro. A autora questiona o uso de gênero como um meio discursivo pelo qual 
a "natureza sexuada" ou "um sexo natural" é produzido e estabelecido como pré-discursivo, uma superfície politicamente neutra sobre a qual age a cultura. Gênero como um domínio pré-discursivo, porém, não seria suficiente para desestabilizar a estrutura binária do sexo, que deveria ser compreendido como efeito do aparato de construção cultural que designamos por gênero. Para Butler (2003), gêneros são performativos no sentido da essência ou identidade que pretendem expressar “. . . são fabricações manufaturadas e sustentadas por signos corpóreos e outros meios discursivos. $\mathrm{O}$ fato de o corpo gênero ser marcado pelo performativo sugere que ele não tem status ontológico separado dos vários atos que constituem sua realidade" (Butler, 2003, p. 194). Se gênero é uma fabricação, uma fantasia instituída e inscrita sobre a superfície dos corpos, então os gêneros não são verdadeiros ou falsos, mas somente produzidos como efeitos da verdade de um discurso sobre a ideia de uma identidade primária estável.

Alinhadas às críticas das formações e nomeações identitárias de gênero, o conceito cisgeneridade foi introduzido por ativistas transfeministas "como um neologismo no sentido de atribuir um nome às matrizes normativas e ideais regulatórios relativos às designações compulsórias das identidades de gênero" (Matos \& Cidades, 2016, p. 133), que se transformou em uma proposta política ao direito de auto atribuição identitária. Esse conceito ainda carrega uma denúncia a uma suposta "identidade de gênero normal" em contraponto a uma transexualidade construída como desvio e patologia. Outro aspecto decorrente dessas problematizações é a noção de mulheridade trans como integrante da própria noção de mulheridade e a homenzidade trans da homenzidade plena, ressignificando os sentidos das palavras "mulher" e "homem" (Rodovalho, 2017).

\section{Nas ondas dos feminismos}

Em uma linha histórica recente, consideramos que a emergência do conceito de gênero ocorreu a partir da segunda metade do século XX, e sua evolução, em grande parte, tem sido acompanhada no tempo vivido pelas autoras deste artigo. Consideramos importante usar o marcador histórico das ondas, períodos e fases dos feminismos para contextualizar a emergência do conceito de gênero e seus desdobramentos.

A noção de "onda" - apesar de problematizada por ser reducionista e dar a impressão de que as ondas são lineares e de que cada uma delas ultrapassa a anterior - ainda nos serve, como afirma Nogueira (2017, p. 25) "para dar uma ideia de fluxo de massa, pessoas, grupos e de movimento com um certo grau de coerência em termos temporais".

Considera-se que a primeira onda se situa em meados do século XIX e vai até cerca dos anos 1960, podendo ser representada pelo movimento sufragista que reivindica o direito ao voto, os direitos civis e a "luta pela igualdade dos direitos contratuais e de propriedade e contra a subordinação das mulheres ao casamento e aos maridos" (Carneiro, 2015, p. 245). A segunda onda é caracterizada pela luta contra a opressão feminina em diversos âmbitos: no trabalho, na família e na política; como a onda dos direitos sociais, pela igualdade e ocupação de espaços centrais no mundo público, da revolução sexual a partir do advento da pílula anticoncepcional e o combate à violência contra a mulher. Iniciam-se a crítica ao etnocentrismo, as lutas anticolonialistas, e emerge o feminismo negro (Nogueira, 2017; Carneiro, 2015). É nessa fase que são assinados os principais marcos legais e que se criam os mecanismos de políticas públicas para mulheres no Brasil. As críticas pós-estruturalistas e pós-modernas direcionadas ao racionalismo essencialista e às categorias de gênero e de subjetividade do feminismo hegemônico da época apontam para o que chamamos de terceira onda do feminismo. Essa onda apresenta um compromisso com a diversidade e a pluralidade que faltavam ao feminismo da segunda onda (Nogueira, 2017).

Os posicionamentos transfeministas, localizados entre o final da década de 1990 e início dos anos 2000, também caracterizam a terceira onda, revelando novas maneiras de ampliar os estudos de gênero. O transfeminismo denuncia a ordem cisheteronormativa e o binarismo das diferenças de sexo ao afirmar a complexidade da intersecção múltiplas de pertenças. Essa vertente "compartilha a necessidade de posicionar e incluir sujeitos transgêneros - abarcando identificações de travestis e transexuais - até então silenciados, frente às teorias e estudos de gênero, como as teorias queer, e às diversas correntes feministas" (Bagagli, 2013, p. 13) e, embora sejam comuns nos espaços virtuais, ainda são escassos nos estudos acadêmicos. Nessa abordagem, novos conceitos são tensionados e a cisgeneridade emerge como crítica ao sistema político baseado na cisnormatividade e cisgeneridade compulsória. 


\section{0 desenho metodológico da pesquisa de estudos de gênero em periódicos de psicologia}

O desenho metodológico adotado é de uma pesquisa histórica realizada por meio de levantamento na base de dados da Scientific Electronic Library Online (SciELO) dos periódicos brasileiros de psicologia disponíveis on-line. A SciELO foi escolhida por ter sido criada há 15 anos e ter uma grande capacidade de indexação, sendo considerada confiável, segura e prática o suficiente para os fins desta pesquisa. Fizemos uso de métodos qualitativos e quantitativos por entendermos que em uma mesma pesquisa empírica podemos "produzir, manusear, analisar e interpretar dados quantitativos e dados qualitativos, com igual legitimidade científica e pelas melhores razões" (Matos, 2014, p. 5).

\section{Dos caminhos e resultados sobre as publicações em gênero e psicologia nos periódicos pesquisados}

A primeira etapa do levantamento buscou, nos periódicos de psicologia, o descritor "gênero". Encontramos, como resultado, 483 artigos assim distribuídos em 12 periódicos (Gráfico 1):

\section{Gráfico 1}

Número de artigos com descritor "gênero" em periódicos de psicologia do portal SciELO.

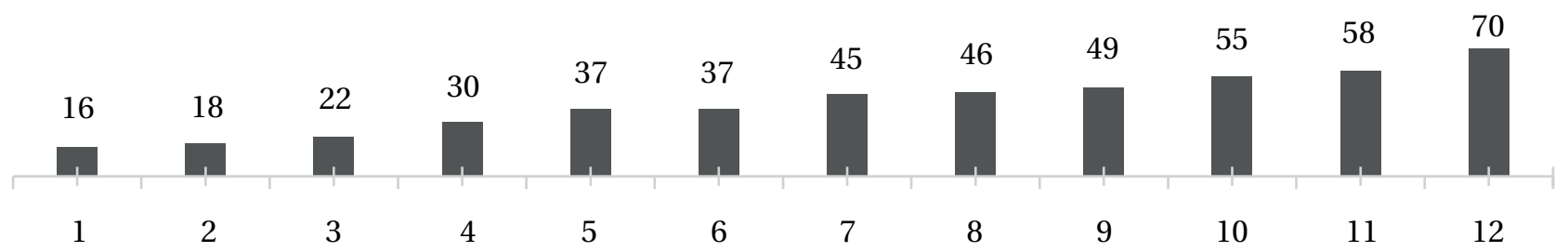

A partir desse levantamento foram estabelecidos critérios de inclusão e exclusão para a escolha dos periódicos a serem analisados na pesquisa: diversidade regional e editorial; antiguidade do periódico; pontuação no Qualis (Capes); representatividade do periódico e disponibilidade virtual. Seguindo esses critérios, foram escolhidos três periódicos: a revista Psicologia \& Sociedade, da Associação Brasileira de Psicologia Social (Abrapso), na época com editoria sediada na região Sudeste, Qualis (Capes) A2; a revista Psicologia, Ciência e Profissão, do Conselho Federal de Psicologia (CFP), sediada no Centro-Oeste,
Qualis (Capes) A2, e a revista Estudos de Psicologia, dos Programas de Pós-Graduação em Psicologia e em Psicobiologia da Universidade Federal do Rio Grande do Norte, sediada na região Nordeste, com Qualis (Capes) Al. Nas três revistas encontramos 153 artigos, sendo 70 da revista Psicologia e Sociedade, 46 da Revista Psicologia, Ciência e Profissão e 37 da revista Estudos de Psicologia. Como primeira sistematização dos dados, foram realizadas tabelas para cada um dos três periódicos em que constam ano, título do artigo, palavras chaves, categoria temática, autores(as) e instituição dos autores(as) (Quadro 1).

Quadro 1

Mapeamento das publicações da revista Psicologia e Sociedade.

\begin{tabular}{|c|c|c|c|c|c|}
\hline Ano & Nome do artigo & Palavras-Chave & $\begin{array}{l}\text { Categoria } \\
\text { Temática }\end{array}$ & Autores (as) & Instituição \\
\hline 2016 & $\begin{array}{l}\text { Gênero, feminismo e } \\
\text { psicologia social no } \\
\text { Brasil, Análise da Revista } \\
\text { Psicologia e Sociedade } \\
(1996-2010)\end{array}$ & $\begin{array}{l}\text { Gênero; } \\
\text { feminismos; } \\
\text { Psicologia Social; } \\
\text { Psicologia \& } \\
\text { Sociedade. }\end{array}$ & Psicologia & $\begin{array}{l}\text { Luana Carola dos } \\
\text { Santos; Ana Berlado } \\
\text { Carvalho; Julião } \\
\text { G. Amaral; Larissa } \\
\text { Amorim Borges; } \\
\text { Claudia Mayorga }\end{array}$ & $\begin{array}{l}\text { Universidade } \\
\text { Federal de } \\
\text { Minas Gerais } \\
\text { (UFMG) }\end{array}$ \\
\hline
\end{tabular}


Os dados dessas tabelas foram sistematizados em gráficos e outras tabelas. Para fins de classificação, criamos 15 categorias temáticas que expressam as palavras-chaves. Consideramos que os artigos poderiam ser agrupados de inúmeras outras maneiras que produziriam outras categorizações. Contudo, optamos por fazer dessa forma por considerarmos que as palavras-chave contêm informações importantes que auxiliam na compreensão do conteúdo dos artigos. Por exemplo, na categoria "trabalho" (Quadro 2), agrupamos por afinidade temática as seguintes palavras-chave:

\section{Quadro 2}

Exemplo da categoria temática "trabalho" a partir do agrupamento de palavras-chave.

\begin{tabular}{|c|c|}
\hline $\begin{array}{l}\text { Categoria } \\
\text { temática }\end{array}$ & Palavras-chave \\
\hline Trabalho & $\begin{array}{l}\text { Desempenho no trabalho, satisfação } \\
\text { no trabalho, treinamento, avaliação } \\
\text { de necessidades, autoavaliação, } \\
\text { aptidão, criatividade, orientação } \\
\text { vocacional, avaliação, trabalho } \\
\text { feminino, cooperativa de produção, } \\
\text { economia solidária, assédio } \\
\text { moral, psicologia organizacional, } \\
\text { tarefas domésticas, dupla carreira, } \\
\text { trabalho, tempo, identidade } \\
\text { profissional, trabalho e identidade, } \\
\text { empoderamento, trabalho social, } \\
\text { empreendedorismo, conflito família } \\
\text { e trabalho, gênero e trabalho. }\end{array}$ \\
\hline
\end{tabular}

As 15 categorias estão apresentadas no Gráfico 2:

Das 15 categorias temáticas construídas a partir palavras-chave dos 153 artigos, cinco se destacaram:
23 (15\%) referiam-se à saúde; $22(14,3 \%)$ à sexualidade; $21(13,7 \%)$ à violência (doméstica, contra a mulher); 19 (12,4\%) à questão do trabalho; e, finalmente, 15 (9,8\%) à educação.

Segundo as palavras-chave dos artigos, a categoria "Saúde" aborda temas como: saúde da família; saúde pública; agente comunitário de saúde; saúde da mulher; do homem; na adolescência; HIV/aids; menopausa; estresse; qualidade de vida; uso abusivo de drogas; câncer de mama; depressão; psicóticos; gravidez; atividade física; saúde bucal; saúde ocupacional e deficiência.

A psicologia, segundo a Resolução CNS no 218, de 1997, do Ministério de Saúde, é reconhecida como uma das 13 categorias profissionais de nível superior que compõem a área da saúde. A Psicologia da Saúde é uma das áreas de especialização descritas na Resolução CFP 03/2016. Educação e Trabalho são contemplados no último documento de revisão das diretrizes curriculares nacionais para os cursos de graduação em psicologia como conhecimentos fundamentais para a gestão e práticas das políticas públicas (Conselho Federal de Psicologia, 2018b). Assim, consideramos que Saúde, Educação e Trabalho são categorias oriundas de áreas mais tradicionais do campo disciplinar da Psicologia. Por exemplo: no currículo mínimo aprovado em 1962 pelo Conselho Federal de Educação, no Parecer 403/1962, já aparecem funções do psicólogo que se referem a essas áreas, na época mais compreendidas como, diagnóstico psicológico, orientação e seleção de pessoal, orientação psicopedagógica e solução de problemas de ajustamento (Conselho Federal de Educação, 1962).

Gráfico 2

Número de artigos por categorias temáticas oriundas das palavras-chave.

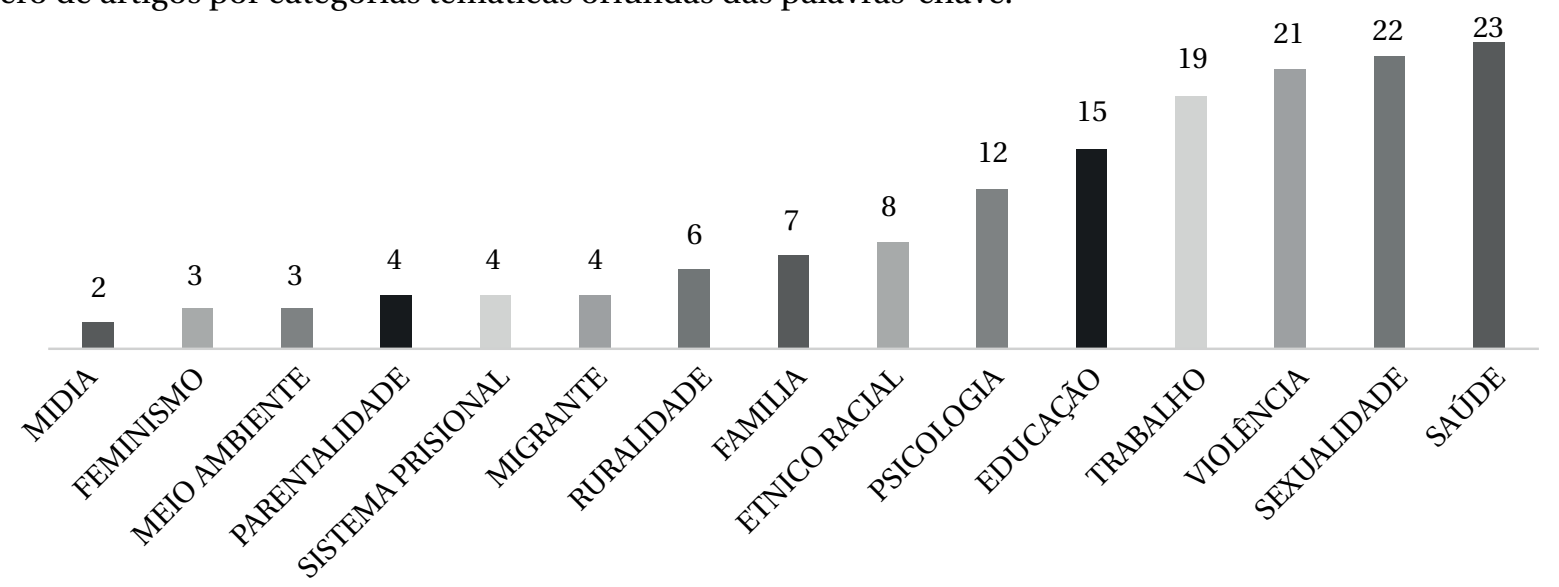


A categoria "sexualidade" agrega artigos com as palavras-chave: sexualidade; travesti; transexual; práticas sexuais; valores sexuais; estudos queer, corpos vibráteis; transexualidade; transexualismo: operação; cirurgia; subjetividade; homoerotismo; homossexualidade feminina; masculinidade; história da sexualidade; prostituição juvenil; intersexualidade; hermafroditismo e identidade de gênero e sexual. Essa categoria apresenta as recentes problematizações das formações identitárias de gênero em alguns poucos artigos que abordam a teoria queer, transexualidades, instersexualidades e masculinidades, demonstrando ainda uma posição cisheteronormativa em grande parte das publicações da psicologia.

Os artigos agrupados na categoria "violência" segundo as palavras-chave tratam dos seguintes temas: violência contra as mulheres; violência na família; conflito conjugal; preconceito: discriminação; violência sexual; Lei Maria da Penha; violência de gênero; raça/cor; violência e afeto; violência doméstica; agressão sexual; casa abrigo; submissão e homem agressor. A violência no Brasil é considerada um problema de saúde pública desde 2001, quando foi inserida na Política Nacional de Redução da Morbimortalidade por Acidentes e Violência (PNRMAV), também se tornando prioridade por meio da criação da Política Nacional de Enfrentamento à Violência contra as Mulheres com a criação da Lei Maria da Penha (Lei $\mathrm{n}^{\circ} 11.340$, de 7 de agosto de 2006). As categorias temáticas agrupadas pelas palavras-chave das publicações parecem estar vinculadas às prioridades e vinculações profissionais, acadêmicas e das políticas públicas do período pesquisado.

\section{Dos autores e autoras que publicam em gênero e psicologia nos periódicos pesquisados}

Dos 402 autores(as) que publicaram os 153 artigos, 289 (71,8\%) são mulheres e 113 (28,01\%) são homens.

Gráfico 3

Sexo dos autores (as) que publicaram nos 153 artigos pesquisados.

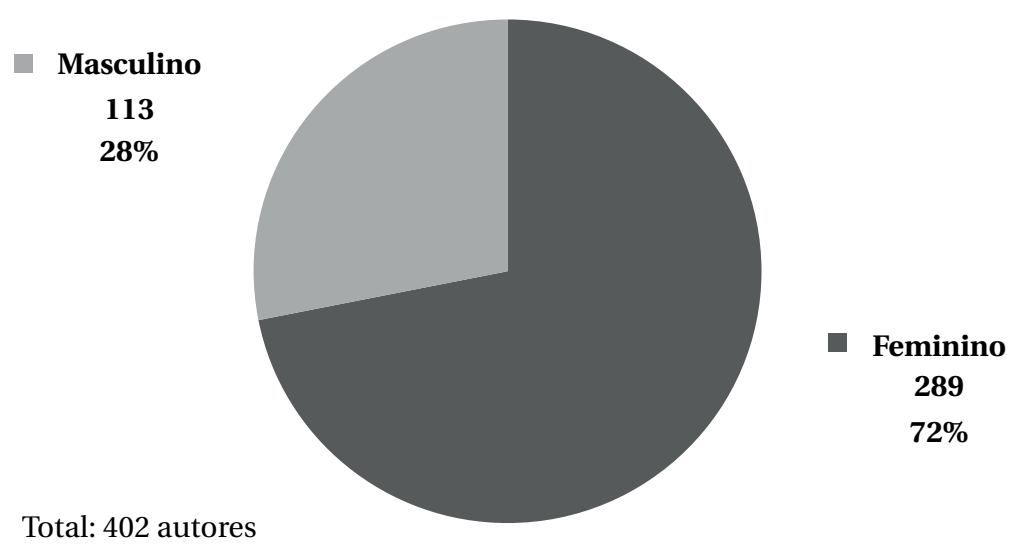

As mulheres são a maioria dos que publicam sobre gênero e psicologia nesta pesquisa. Contudo, problematizamos o uso da categoria "sexo" com base nos atributos biológicos sugeridos pelo nome dos autores(as), o que invisibiliza outras possibilidades de identificação engendradas, como lésbicas, gays, bissexuais, travestis, transexuais, transgêneros e outros (LGBTQIA+). Esses dados apontam a forma restrita de identificação do sistema sexo/gênero disponível nas bases de dados dos periódicos. Quando usamos somente o nome dos(as) autores(as) como forma de identificação do gênero, estamos legitimando o sexo biológico e a dicotomia feminino e masculino como as únicas possibilidades identitárias, o que impede o reconhecimento da autoria de outros gêneros, colocando-os em posição de anonimato. De qualquer forma, no levantamento foi possível identificar 402 autores(as) que publicaram nos três periódicos pesquisados, dos quais destacamos Maria Juracy Filgueiras Toneli (UFSC), com dez artigos; Valdiney Veloso Gouveia (UFPB), com quatro artigos; e Benedito Medrado (UFPE) com quatro artigos. Os demais 399 autores(as) publicam entre um e três artigos, o que aponta para uma diversificação e pulverização das autorias e instituições. 


\section{Gráfico 4}

Parcial dos autores (as) que mais publicam em Gênero e Psicologia nos três periódicos pesquisados.

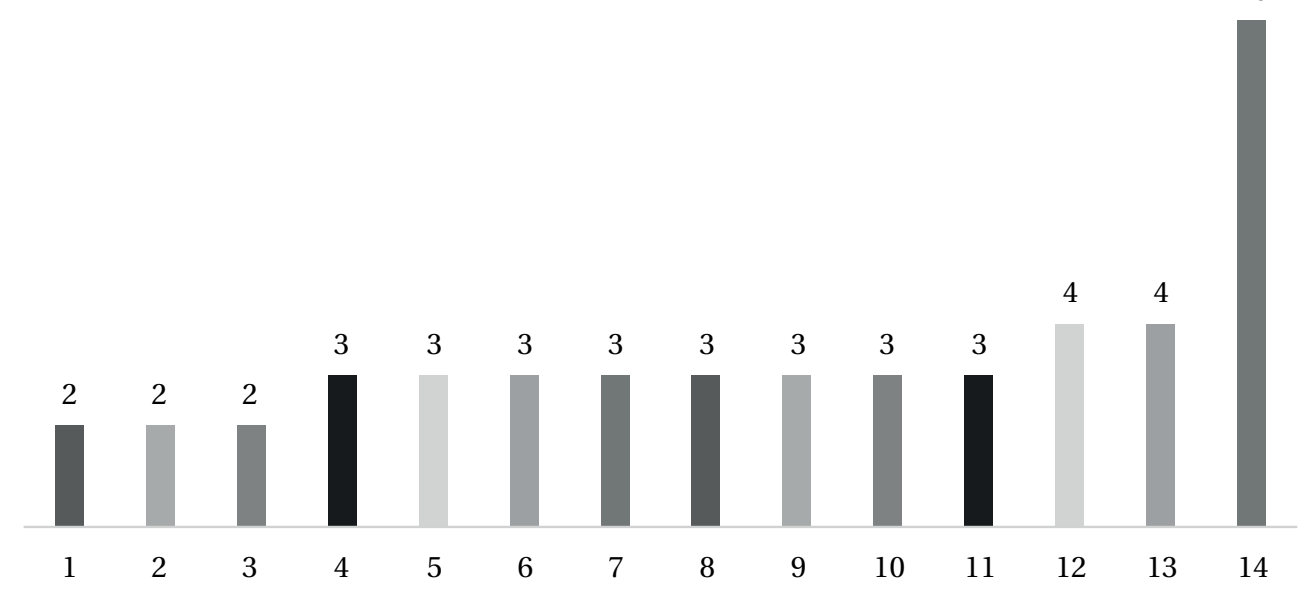

Destacamos que entre os 10 autores(as) que mais publicam, seis são do sexo masculino e quatro, do sexo feminino. Isso indica que, mesmo com as mulheres perfazendo $72 \%$ do total de autores(as) pesquisados e compondo $89 \%$ da profissão de psicólogos(as) (Conselho Federal de Psicologia, 2018a), quando se realiza uma análise de gênero dentre os que mais publicam, constata-se assimetria e desigualdade. A Análise de Gênero Ocupacional que indica a posição relacional ocupada pelas pessoas do sexo feminino e masculino em determinada instituição, setor ou área, tem sido usada para revelar as hierarquias de gênero mesmo em ambientes onde a maioria seja composta por mulheres ou pessoa do sexo feminino. Entretanto, não foi nosso objetivo fazer este tipo de análise neste estudo.

\section{Das instituições dos autores(as) que publicam em gênero e psicologia pesquisados}

Do ranking das 195 instituições dos autores(as) que publicam em gênero e psicologia, a Universidade Federal de Santa Catarina (UFSC) apresentou 18 artigos; a Universidade de Brasília (UnB), 16 artigos e a Universidade de São Paulo (USP), 11 artigos. Dentre as dez instituições que mais publicam, encontram-se as universidades públicas, sendo sete federais, duas estaduais e uma internacional.

\section{Gráfico 5}

Instituições dos autores que publicam mais artigos em gênero e psicologia.

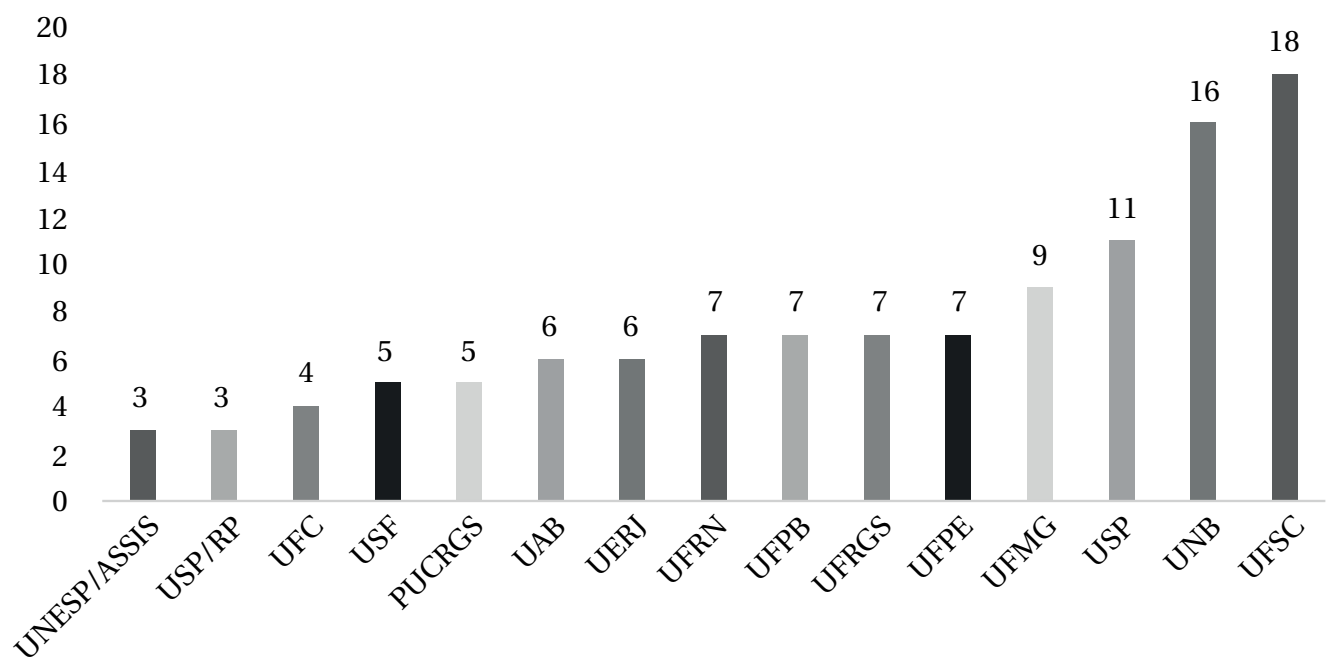


Da UniversidadeFederal de Santa Catarina (UFSC), 11 artigos foram publicados na revista Psicologia e Sociedade, sete na revista Ciência e Profissão e um na Estudos de Psicologia. Da Universidade de Brasília (UnB), quatro artigos foram publicados na revista Psicologia e Sociedade, cinco na Ciência e Profissão e sete na revista Estudos de Psicologia. Dentre os artigos da Universidade de São Paulo (USP), cinco foram publicados na revista Psicologia e Sociedade, três na revista Ciência e Profissão e três na Estudos de Psicologia.

As parcerias para publicações nas distintas revistas se apresentam bem definidas, seja em função de alinhamentos teórico-metodológicos, afiliações associativas, posicionamentos críticos ou abrangência territorial. Por exemplo: a revista Estudos de Psicologia (UFRN) publica artigos que se alinham aos programas de pós-graduação mais empiristas, expressos por uma significativa presença de artigos oriundos de programas da UnB, USP, Universidade São Francisco (USF) e Universidade Federal do Rio Grande do Sul (UFRGS). Na revista Psicologia e Sociedade, as parcerias ocorrem em razão da relação dos autores com os posicionamentos críticos dos afiliados à Abrapso. Os artigos mais recorrentes são das instituições que sediaram recentemente a revista, como UFSC, Universidade Federal de Minas Gerais (UFMG) e Universidade Federal de Pernambuco (UFPE). A revista Psicologia Ciência e Profissão é a que tem maior pulverização de artigos oriundos de instituições públicas e privadas, atendendo à diversidade e cobertura regional da categoria dos/das psicólogos(as), inclusive com muitos trabalhos das regiões Norte e Centro-Oeste.

\section{Análise dos resultados das publicações em gênero e psicologia nos periódicos pesquisados}

Descrevemos a seguir as opções de análise qualitativa dos dados relativas ao objetivo da pesquisa de compreender como os estudos de gênero se situam historicamente na psicologia para mapear os diferentes usos do conceito de gênero dessas referências e problematizar os efeitos nas teorizações psicológicas. Primeiramente, realizamos a leitura dos resumos / abstracts dos 153 artigos. Dessa leitura, observamos que a grande maioria dos artigos trata de questões temáticas e eram poucos os que tratavam de questões teóricas da relação entre gênero e psicologia.

Uma análise possível foi a utilização dos marcadores históricos das Ondas Feministas (Carneiro, 2015;
Nogueira, 2017) descritas anteriormente para pensar as categorias temáticas organizadas pelas palavras-chave. Das categorias temáticas construídas, não identificamos nenhuma que apresentasse questões da primeira onda, do sufragismo relacionado ao voto feminino; ou seja, em relação aos direitos civis. A grande maioria é alinhada à segunda onda do feminismo, tratando de temas oriundos da conquista de direitos sociais como saúde, educação, trabalho, família e meio ambiente. Fazendo fronteira entre a segunda e terceira onda, em que se apresentam atores(as) emergentes, identificamos as categorias etnorracial, imigrantes, sistema prisional e ruralidades, por abrangerem sujeitos e questões não mais hegemônicos e típicos do feminismo da segunda onda. Nas categorias de sexualidade, feminismos, psicologia e mídia, encontramos temas oriundos da terceira onda por já conterem críticas à universalidade do sujeito do feminismo, às epistemologias tradicionais da modernidade e à disciplinaridade, às teorizações do transfeminismo e cisgeneridade, expressos em artigos que discutem a teoria queer, os estudos interseccionais de gênero, as masculinidades, a intersexualidade e a corporeidade, que vão além das análises descritivas de gênero.

A partir dessa classificação a partir das ondas do feminismo, escolhemos 12 artigos agrupados nas categorias feminismo e psicologia por entendermos que eles nos dariam maior possibilidade de analisar as questões propostas pelos objetivos da pesquisa.

$\mathrm{Na}$ categoria feminismo encontramos as seguintes palavras-chave: conceito de gênero; gênero; feminismo; política; movimentos sociais: encontros feministas; teorias feministas e epistemologias. Já na categoria psicologia, encontramos: Psicologia Social; feminismo e psicologia: homenagem; produtividade de pesquisa em psicologia; atuação do psicólogo; formação do psicólogo; profissões; Construcionismo Social; Psicologia Comunitária; História da Psicologia; análise de discurso; narrativa oral; autoconceito; esquema feminino; inventário; formação acadêmica e Psicologia no Brasil.

Na revista Estudos em Psicologia, encontramos três artigos classificados na categoria Psicologia e nenhum especificamente sobre feminismo. Em um desses artigos, intitulado "Narrativa oral, análise de discurso e os estudos de gênero" (Rocha-Coutinho, 2006), a autora questiona a objetividade do conhecimento e a impessoalidade do pesquisador na interpretação da realidade social, propondo que uma abordagem pós-empírica poderia contribuir com 
os estudos de gênero na psicologia, especificamente para questões identitárias. Outro artigo se refere à validação de escalas psicológicas, "Inventário feminino dos esquemas de gênero" (Giavoni \& Tamayo, 2005). Esse inventário validado poderia ser usado para avaliar esquemas masculinos e femininos do autoconceito de indivíduos do sexo feminino. O último artigo dessa categoria, "A psicologia como profissão feminina: apontamentos para estudo" (Castro \& Yamamoto, 1998), busca discutir a natureza feminina da Psicologia a partir de dados que demonstram a distribuição desigual de homens e mulheres no curso de psicologia da UFRN enquanto carreira e profissão. Os três artigos apresentam uma diversidade teórico-metodológica que aponta para os variados aspectos com que os estudos de gênero podem impactar a Psicologia, tendo o primeiro o objetivo de trazer novos desafios metodológicos à disciplina, o segundo o de introduzir os esquemas de gênero nos inventários psicológicos e o último a discussão sobre a composição de gênero da categoria e carreira profissional de psicologia.

Dos cinco artigos da revista Psicologia: Ciência e Profissão, dois tratam de perfis dos(as) psicólogos(as). Um é sobre o perfil de pesquisadores bolsistas do CNPq, em que as autoras recomendam que disparidades de gênero devem ser reavaliadas (Sacco et al., 2016). Outro é um levantamento do perfil profissional de psicólogos(as) inscritos em uma subsede do CRP04 de Governador Valadares, em Minas Gerais (Santos, Monteiro, Torres, Sousa, \& Coelho, 2014) confirmando a prevalência de $88 \%$ do sexo feminino, o que corrobora a média nacional do perfil profissional. Os autores apontam que a importância de se observar essa variável, além da questão do mercado de trabalho, "pode estar relacionado com a cultura, na medida em que é, habitualmente, a mulher que mais valoriza as questões emocionais e sentimentais, enquanto o homem valoriza as questões mais racionais e de ordem prática" (Santos et al., 2014, p. 875). Essa explicação do perfil profissional de psicológos(as) é uma forma essencializadora e binária típica de uma análise descritiva do gênero.

A formação em psicologia e as problematizações a respeito das novas configurações de gênero são temas do artigo de Melo \& Barreto (2014), que se propõe a cartografar as produções de saberes no campo da Psicologia e os efeitos na formação dos acadêmicos de psicologia. Segundo as autoras,
É neste cenário onde se é discutido questões relevantes sobre o gênero, diversidade sexual e sexualidade dissidentes, que a Psicologia como uma das ciências que tem a subjetividade como fonte de estudo, vem se reavaliando teórica-metodologicamente nas suas práticas psi, além dos discursos/saberes agenciados na sua formação (Melo \& Barreto, 2014, p. 687).

Ainda em relação à questão de gênero e sexualidade na psicologia, o artigo "Abordagens de gênero e sexualidade na psicologia: revendo conceitos, repensando práticas" (Borges, Canuto, Oliveira, \& Vaz, 2013) analisa, a partir das produções acadêmicas do Curso de Psicologia e do Programa de Pós-graduação da Pontifícia Universidade Católica de Goiás (PUC-Goiás), as perspectivas teóricas privilegiadas na descrição do objeto, as áreas e os temas centrais, bem como os avanços e as lacunas da produção acadêmica e a proposta curricular oferecida pelo curso. As autoras criticam a formação e produção da psicologia, concluindo que "o ensino da Psicologia ainda se concentra predominantemente nos estudos das identidades, em uma visão normativa, polarizada e patologizada quanto ao gênero e às sexualidades" (Borges et al., 2013, p. 731).

Em cinco artigos das categorias feminismo e psicologia da revista Psicologia e Sociedade, as autoras falam de feminismos, política, memórias e homenagens. A psicóloga social Karin von Smigay foi homenageada em um ensaio da revista por ser uma estudiosa das relações de gênero e violência e por seu pioneirismo na aproximação dos estudos de gênero e a Psicologia Social, que "tomou como base para narrar a intimidade como campo da política e da democratização das relações de poder entre homens e mulheres" (Prado, Maheirie, Medrado, \& Caniato, 2011, p. 202). Um artigo que usa a metodologia de história oral relata as experiências e memórias das narrativas autobiográficas de três mulheres de uma comunidade pobre próxima a Fortaleza (CE). Segundo as autoras, "as narradoras favorecem uma linha de intriga que as dispõe como mulheres frágeis, porém guerreiras, enfrentando bravamente as adversidades desde tenra idade" (Brandão \& Germano, 2009, p. 13). $\mathrm{O}$ artigo das autoras Adrião e Toneli $(2008$, p. 13) discute o tema dos "sujeitos feministas no campo político levando em consideração as transformações discursivas pelas quais o campo do movimento feminista vem passando nas últimas décadas". Entretanto, 
o artigo, ao analisar o sujeito do feminismo a partir de dois Encontros Feministas Latino-Americano e do Caribe $(1985,2005)$, não os relaciona com a psicologia enquanto campo teórico ou político. Em outro artigo, Perucchi, Toneli, \& Adrião (2013) trazem questionamentos sobre Psicologia Social e sobre a academia em geral a partir das epistemologias feministas. Para as autoras, "o debate feminista não é separado do campo científico em geral, relativo ao estatuto da ciência e das formas de geração de conhecimento, e também presente no campo da Psicologia Social" (Perucchi, Toneli, \& Adrião, 2013, p. 13). O artigo recomenda que toda pesquisa que se considere "feminista" faça uso de outras epistemologias para sair do lugar "androcentric, ethnocentric, classism and heterosexist" (Perucchi, Toneli, \& Adrião, 2013, p. 20) ainda presente no cenário acadêmico. Um levantamento das publicações sobre gênero e psicologia foi analisado no artigo das autoras Santos, Carvalho, Amaral, Borges, \& Mayorga (2016), "Gênero, feminismo e psicologia social no Brasil: análise da revista Psicologia \& Sociedade (1996-2010)", em que o interesse era analisar como, no contexto brasileiro, tais críticas à noção de gênero por feministas da terceira onda teriam marcado a produção em Psicologia Social. Foram analisados 36 artigos do periódico publicados entre os anos de 1996 e 2010. A partir da leitura dos títulos, resumos, palavras-chave e alguns artigos completos, escolheram aqueles que estavam relacionados à questão de gênero e/ou da mulher. As autoras construíram um modelo analítico a partir do uso do conceito de gênero e poder para identificar se gênero aparecia mais como uma categoria descritiva ou associado à teoria feminista. Como resultado e contribuição à psicologia, as autoras consideraram esse exercício indispensável por "reconhecer a pluralidade e localizar as referências e as perspectivas de gênero distintos que embasam as produções em psicologia" (Santos, Carvalho, Amaral, Borges, \& Mayorga, p. 601).

\section{Considerações finais}

Do que foi descrito e analisado acima, quantitativa e qualitativamente, podemos depreender as seguintes conclusões:

- As mulheres são a maioria dos que publicam na área de gênero, mas não estão entre as que mais publicam;
- Entre as instituições dos autores(as), o maior número de publicações encontra-se nas universidades públicas;

- Há uma diversificação e pulverização das autorias, o que indica uma pequena concentração de artigos por autores(as);

- O debate sobre gênero na Psicologia ocorre por meio de discussão temáticas de campos de conhecimento tradicionais como saúde, educação, trabalho e violência, o que caracterizaria a segunda onda do feminismo;

- As discussões identitárias da sexualidade e gênero que abordam as teorizações de gênero da terceira onda, como a teoria queer, transexualidade, cisgeneridade, transfeminismo, instersexualidade, masculinidades etc., são mais escassas e bem recentes;

- Alguns artigos apontam críticas epistemológicas à psicologia, questionando o uso descritivo de gênero, a objetividade do conhecimento, a universalidade do sujeito e ainda apresentam dificuldades de sair do lugar androcêntrico, etnocêntrico, classista e heterossexista que caracteriza a produção de conhecimento na área da psicologia.

O cenário apresentado da relação entre os estudos de gênero e psicologia aponta, portanto, que, apesar do número expressivo de publicações e autores que estão publicando sobre gênero na área de psicologia, não podemos considerar que estejam alterando de forma significativa as teorias e métodos das principais abordagens psicossociais da psicologia. As aproximações são mais com questões temáticas, em que se empresta os conhecimentos feministas para as análises de problemas psicossociais, sem haver, contudo, um impacto nas teorizações da psicologia - apesar de alguns posicionamentos críticos e denúncias contundentes. Isso demonstra um distanciamento com as teorizações e epistemologias feministas e de gênero. Diante dessas considerações, propomos uma maior sensibilização para que espaços de discussão das relações entre gênero e psicologia sejam ampliados e se tornem mais do que uma forma de fazer psicologia engendrada, mas também de resistir às invisibilidades ainda tão persistentes em nosso campo de conhecimento. 


\section{Referências}

Adrião, K. G., \& Toneli, M. J. F. (2008). Por uma política de acesso aos direitos das mulheres: Sujeitos feministas em disputa no contexto brasileiro. Psicologia \& Sociedade, 20(3), 465-474. https://doi.org/10.1590/ S0102-71822008000300017

Bagagli, B. P. (2016). Máquinas discursivas, ciborgues e transfeminismo. Revista Gênero, 14(1), 11-27.https://doi.org/ $10.22409 /$ rg.v14il.606

Beauvoir, S. (2019). O segundo sexo: A experiência vivida. Nova Fronteira. (Trabalho original publicado em 1948)

Borges, L. S., Canuto, A. A. A., Oliveira, D. P., \& Vaz, R. P. (2013). Abordagens de gênero e sexualidade na psicologia: Revendo conceitos, repensando práticas. Psicologia: Ciência e Profissão, 33(3), 730-745. https://doi.org/10.1590/ S1414-98932013000300016

Brandão, T. O., \& Germando, I. M. P. (2009). Experiência, memória e sofrimento em narrativas autobiográficas de mulheres. Psicologia \& Sociedade, 21(1), 5-15. https://doi.org/10.1590/S0102-71822009000100002

Butler, J. (2003) Problemas de gênero: Feminismo e subversão da identidade (R. Aguiar, Trad.). Civilização Brasileira.

Carneiro, M. E. R. (2015). Feminismo-feminismos. In A. M. Colling, \& L. Tedeschi, Dicionário crítico de gênero (pp. 251-255). UFGD.

Castro, A. E. F., \& Yamamoto, O. H. (1998). A psicologia como profissão feminina: Apontamentos para estudo. Estudos de Psicologia (Natal), 3(1), 147-158. https://doi.org/10.1590/S1413-294X1998000100011

Conselho Federal de Educação. (1962). Parecer no 403/62 do Conselho Federal de Educação. Arquivos Brasileiros de Psicologia Aplicada, 28(4), 244-246. http://bibliotecadigital.fgv.br/ojs/index.php/abpa/article/ view/17799/16543

Conselho Federal de Psicologia. (2018a). Infográfico: A psicologia brasileira apresentada em números. Conselho Federal de Psicologia. http://www2.cfp.org.br/infografico/quantos-somos/

Conselho Federal de Psicologia. (2018b). Ano da formação em psicologia: Revisão das diretrizes curriculares nacionais para os cursos de graduação em psicologia. Conselho Federal de Psicologia, Associação Brasileira de Ensino de Psicologia, Federação Nacional dos Psicólogos. https://site.cfp.org.br/wp-content/uploads/2018/07/ RELAT\%C3\%93RIO-FINAL-REVIS\%C3\%83O-DAS-DIRETRIZES-CURRICULARES-NACIONAIS-PARA-OSCURSOS-DE-GRADUA\%C3\%87\%C3\%83O-EM-PSICOLOGIA.PDF

Dias, M. O. L. S. (1992). Teoria e método dos estudos feministas: Perspectiva histórica e hermenêutica do cotidiano. In A. O. Costa, \& C. Bruschini (Orgs.), Uma questão de gênero (pp. 39-53). Rosa dos Tempos.

Federici, S. (2019). O ponto zero da revolução: Trabalho doméstico, reprodução e luta feminista. Elefante.

Giavoni, A., \& Tamayo, Á. (2005). Inventário feminino dos esquemas de gênero do autoconceito (Ifega). Estudos de Psicologia, 10(1), 25-34. https:// doi.org/10.1590/S1413-294X2005000100004

Grossi, M. P., Heilborn, M. L., \& Rial, C. (1998). Entrevista com Joan Wallach Scott. Revista Estudos Feministas, 6(1), 114-124. https://doi.org/10.1590/\%25x

Heilborn, M. L. (2004). Dois é par: Gênero e identidade sexual em contexto igualitário. Garamond.

Hirata, H. (Org.). (2009). Dicionário crítico do feminismo. Editora Unesp.

Jesus, J. G., \& Alves, H. (2012). Feminismo transgênero e movimentos de mulheres transexuais. Revista Cronos, 11(2), 1-12. https://periodicos.ufrn.br/cronos/article/view/2150

Kergoat, D. (2009). Divisão sexual do trabalho e relações sociais de sexo. In H. Hirata et al. (Org.), Dicionário crítico do feminismo (pp. 67-75). Editora Unesp.

Lei $n$. 11.340, de 7 de agosto de 2006. (2006). Cria mecanismos para coibir a violência doméstica e familiar contra a mulher, nos termos do $\$ 8^{\circ}$ do art. 226 da Constituição Federal, da Convenção sobre a Eliminação de Todas as Formas de Discriminação contra as Mulheres e da Convenção Interamericana para Prevenir, Punir e Erradicar a Violência contra a Mulher, e dá outras providências. Presidência da República. http://www.planalto.gov.br/ ccivil_03/_ato2004-2006/2006/lei/111340.htm

Matos, M. (2014). Metodologias qualitativas e quantitativas: De que falamos? Fórum Sociológico, 24, 1-14. https://doi.org/10.4000/sociologico.1061 
Mattos, A., \& Cidade, M. (2016). Para pensar a cisheteronormatividade na psicologia: Lições tomadas do transfeminismo. Revista Periódicus, 1(5), 132-153. https://doi.org/10.9771/peri.vli5.17181

Melo, R. A., \& Barreto, D. J. (2014). Formação em psicologia: Discursos e saberes sobre experimentações de gênero. Psicologia: Ciência e Profissão, 34(3), 676-689. https://doi.org/10.1590/1982-3703000932012

Money, J. (1955). Hermaphroditism, gender and precocity in hyperadrenocorticism: Psychologic findings. Bulletin of the Johns Hopkins Hospital, 96(6), 253-264. http://europepmc.org/article/med/14378807

Nogueira, C. (2017). A interseccionalidade e psicologia feminista. Devires.

Perucchi, J., Toneli, M. J. F., \& Adrião, K. G. (2013). Gender and feminisms: Theoretical-epistemological considerations and methodological impacts. Psicologia \& Sociedade, 25(spe), 13-22. https://doi.org/10.1590/ S0102-71822013000500003

Prado, M. A. M., Maheirie, K., Medrado, B., \& Caniato, A. (2011). Nas trilhas de um pensamento complexo sobre relações de gênero e a psicologia social no cotidiano: Homenagem para Karin Ellen von Smigay. Psicologia \& Sociedade, 23(1), 201-203. https://doi.org/10.1590/S0102-71822011000100024

Rocha-Coutinho, M. L. (2006). A narrativa oral, a análise de discurso e os estudos de gênero. Estudos de Psicologia (Natal), 11(1), 65-69. https://doi.org/10.1590/S1413-294X2006000100008

Rodovalho, A. M. (2017). O cis pelo trans. Revista Estudos Feministas, 25(1), 365-373. https://doi.org/ $10.1590 / 1806-9584.2017 \mathrm{v} 25 n 1 \mathrm{p} 365$

Rubin, G. (1993). O tráfico de mulheres: Notas sobre a "economia política" do sexo. S.O.S. Corpo. (Trabalho original publicado em 1975)

Sacco, A. M., Valiente, L., Vilanova, F., Wendt, G. W., De Sousa, D. A., \& Koller, S. H. (2016). Perfil dos bolsistas de produtividade em pesquisa do CNPq atuantes em psicologia no triênio 2012-2014. Psicologia: Ciência e Profissão, 36(2), 292-303. https://doi.org/10.1590/1982-3703002702015

Saffioti, H. I. I. B. (2015). Primórdios do conceito de gênero. Cadernos Pagu, (12), 157-163. https://periodicos.sbu. unicamp.br/ojs/index.php/cadpagu/article/view/8634812

Santos, K. R., Monteiro, L. G., Torres, M. L. C., Sousa, L. G., \& Coelho, A. R. (2014). Perfil dos psicólogos inscritos na subsede leste do CRP-04. Psicologia: Ciência e Profissão, 34(4), 864-878. https://doi.org/0.1590/1982-370000162013

Santos, L. C., Carvalho, A. B., Amaral, J. G., Borges, L. A., \& Mayorga, C. (2016). Gênero, feminismo e psicologia social no Brasil: Análise da Revista Psicologia \& Sociedade (1996-2010). Psicologia \& Sociedade, 28(3), 589-603. https://doi.org/10.1590/1807-03102016v28n3p589

Scott, J. W. (1995). Gênero: Uma categoria útil de análise histórica. Educação e Realidade, 20(2), 71-99. https://seer.ufrgs.br/educacaoerealidade/article/view/71721-

Scott, J. W. (2007). Prefácio a Gender and Politics of History. Cadernos Pagu, (3), 11-27. (Trabalho original publicado em 1995). https://periodicos.sbu.unicamp.br/ojs/index.php/cadpagu/article/view/1721

Scott, J. W. (2014). Os usos e abusos do gênero (A. C. E. C. Soares, Trad.). Projeto História: Revista do Programa de Estudos Pós-Graduados de História, 45, 327-351. https://revistas.pucsp.br/index.php/revph/article/view/15018

Soihet, R., \& Pedro, J. M. (2007). A emergência da pesquisa da história das mulheres e das relações de gênero. Revista Brasileira de História, 27(54), 281-300. https://doi.org/10.1590/S0102-01882007000200015

Stoller, R. J. (1968). Sex and gender: The development of masculinity and femininity. Science House.

Tilly, L. A. (2007). Gênero, história das mulheres e história social. Cadernos Pagu, (3), 28-62. https:/ / periodicos.sbu. unicamp.br/ojs/index.php/cadpagu/article/view/1722

\section{Jacy Correa Curado}

Professora associada do curso de Psicologia e do Programa de Pós-Graduação em Psicologia da Universidade Federal de Mato Grosso do Sul (UFMS) e da Universidade Federal da Grande Dourados (UFGD), Campo Grande - MG. Brasil. E-mail: jacy.curado@ufms.br

(1) https://orcid.org/0000-0002-7824-0499 
Ana María Jacó-Vilela

Professora titular da Universidade do Estado do Rio de Janeiro (Uerj), Rio de Janeiro - RJ. Brasil.

E-mail: jaco.ana@gmail.com

(D) https:// orcid.org/0000-0002-0728-8700

Endereço para envio de correspondência:

Rua Castro Faria, 345, Monte Castelo. CEP: 79011-030. Campo Grande - MS. Brasil.

Recebido 27/01/2019

Aceito 27/07/2020

Received $01 / 27 / 2019$

Approved 07/27/2020

Recibido 27/01/2019

Aceptado 27/07/2020

Como citar: Curado, J. C, \& Jacó-Vilela, A. M. (2021). Estudos de gênero na psicologia (1980-2016): Aproximações e distanciamentos. Psicologia: Ciência e Profissão, 41, 1-16. https://doi.org/10.1590/1982-3703003219132

How to cite: Curado, J. C, \& Jacó-Vilela, A. M. (2021). Gender studies in psychology (1980-2016): Approximations and distancing. Psicologia: Ciência e Profissão, 41, 1-16. https://doi.org/10.1590/1982-3703003219132

Cómo citar: Curado, J. C, \& Jacó-Vilela, A. M. (2021). Estudios de género en la psicología (1980-2016): Aproximaciones y distanciamientos. Psicologia: Ciência e Profissão, 41, 1-16. https://doi.org/10.1590/1982-3703003219132 